\title{
Radar efficiency and the calculation of decade-long PMSE backscatter cross-section for the Resolute Bay VHF radar
}

\author{
N. Swarnalingam ${ }^{1}$, W. K. Hocking ${ }^{1}$, and P. S. Argall ${ }^{2}$ \\ ${ }^{1}$ Department of Physics and Astronomy, University of Western Ontario, London, Ontario, N6A 3K7, Canada \\ ${ }^{2}$ School of Manufacturing Science, Fanshawe College, London, Ontario, N5Y 5R6, Canada
}

Received: 7 November 2007 - Revised: 19 January 2009 - Accepted: 21 January 2009 - Published: 7 April 2009

\begin{abstract}
The Resolute Bay VHF radar, located in Nunavut, Canada $\left(75.0^{\circ} \mathrm{N}, 95.0^{\circ} \mathrm{W}\right)$ and operating at $51.5 \mathrm{MHz}$, has been used to investigate Polar Mesosphere Summer Echoes (PMSE) since 1997. PMSE are a unique form of strong coherent radar echoes, and their understanding has been a challenge to the scientific community since their discovery more than three decades ago. While other high latitude radars have recorded strong levels of PMSE activities, the Resolute Bay radar has observed relatively lower levels of PMSE strengths. In order to derive absolute measurements of PMSE strength at this site, a technique is developed to determine the radar efficiency using cosmic (sky) noise variations along with the help of a calibrated noise source. VHF radars are only rarely calibrated, but determination of efficiency is even less common. Here we emphasize the importance of efficiency for determination of cross-section measurements. The significant advantage of this method is that it can be directly applied to any MST radar system anywhere in the world as long as the sky noise variations are known. The radar efficiencies for two on-site radars at Resolute Bay are determined. PMSE backscatter cross-section is estimated, and decade-long PMSE strength variations at this location are investigated. It was noticed that the median of the backscatter cross-section distribution remains relatively unchanged, but over the years a great level of variability occurs in the high power tail of the distribution.
\end{abstract}

Keywords. Atmospheric composition and structure (Aerosols and particles) - Meteorology and atmospheric dynamics (Middle atmosphere dynamics; Instruments and techniques) - Radio science (Electromagnetic noise and interference; Remote sensing)

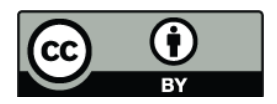

Correspondence to: N. Swarnalingam (nswarna2@uwo.ca)

\section{Introduction}

Polar Mesosphere Summer Echoes (PMSE), which are characterized by strong coherent echoes from the summer cold mesopause region, are a well recognized high latitude phenomenon both in the Northern and Southern Hemispheres. Soon after their unexpected discovery by Ecklund and Balsley (1981), they became a challenge to the scientific community, since the well known radar backscatter theories could not explain their peculiar observed features (see Cho and Kelley, 1993; Cho and Röttger, 1997; Rapp and Lübken, 2004; La Hoz et al., 2006).

Observed high strengths of radar returns from irregularities in the order of a few meters scale and even less have ruled out the possibilities for neutral turbulence to be the sole cause for PMSE (e.g. Czechowsky and Rüster, 1985; Hoppe et al., 1988). Since the Bragg scales of the observed radars fall deep in the viscous subrange of the neutral turbulence energy spectrum, the irregularities that are produced at these scales will be smoothed immediately by molecular diffusion, and hence they cannot produce such a high strength of backscatter signals at the ground. On the other hand, Fresnel reflection theory (also called specular reflections) has also had problems in explaining PMSE. In order to cause Fresnel reflections, there must be narrow steps in refractive index in the vertical direction that are at least a Fresnel zone wide. Also they would have to be highly aspect sensitive (Röttger, 1980). More importantly, their vertical step size should not exceed more than one wavelength if they are to be detected by traditional radar (see Hocking and Röttger, 1997). In the case of PMSE, although in some cases aspect sensitivity is evident, the scatter is isotropic in other cases. So while specular reflections could in part cause PMSE, they cannot be the sole cause.

The observed features convinced researchers that a new theory needed to be developed. The first breakthrough was achieved by Kelley et al. (1987) by linking PMSE with

Published by Copernicus Publications on behalf of the European Geosciences Union. 
cluster ions. They proposed that the diffusivity of the electrons in the polar mesopause could be reduced by heavy positive cluster ions, so that electrons can maintain scales into the so called viscous-convective subrange, and could produce radar echoes. This concept was extended to charged ice particles by Cho et al. (1992). They applied Hill's (1978) multipolar diffusion theory to the mesopause environment, which consists of charged ice particles, positive ions and electrons, and found that if the negatively charged ice particles dominate the plasma charge balance, electrons and charged ice particles will maintain anti-correlated fluctuations due to Coulomb repulsion. Cho et al.'s (1992) theory was further supported by the detection of charged aerosol particles in the mesopause region by rocket probe experiments (Havnes et al., 1996). In recent times, the concepts of fossil turbulence has also been used in an attempt to explain the physical process that causes PMSE. The possible link between PMSE and fossil turbulence was initially described by Cho et al. (1996). This concept was later used by Rapp and Lübken (2003) to explain the existence of PMSE in the absence of neutral turbulence. Nevertheless, understanding the physical processes that cause the small scale fluctuations remains a challenging issue even after intensive multi-level theoretical and experimental studies for almost three decades.

\section{PMSE observations at Resolute Bay}

A multipurpose $51.5 \mathrm{MHz}$ VHF radar system at Resolute Bay $\left(75.0^{\circ} \mathrm{N}, 95.0^{\circ} \mathrm{W}\right)$ provides facilities to conduct various atmospheric experiments from the troposphere to mesosphere (Hocking et al., 2001). For almost a decade, this radar has been monitoring winds, temperatures, tides and other wave activities in this region. In addition, it has been also continuously monitoring PMSE activities for many years. Over the years, while other high latitude radars have observed PMSE activities with a high signal-to-noise ratio, the Resolute Bay radar has observed a relatively low signal-to-noise ratio (Huaman et al., 2001). The Resolute Bay radar system is operated with a $12 \mathrm{~kW}$ peak power transmitter, which is relatively low in power compared with power used at other sites in the European sector. Quantities such as occurrence rates (OR) and the signal-to-noise values (SNR) directly depend on a radar system parameters, and therefore OR and SNR may not be the best parameters to compare the results among multiple sites. In order to derive absolute measurements of PMSE strength at this location, the radar system was carefully calibrated by using a calibrated noise source and the available cosmic noise variations above the site.

\section{Absolute radar calibration using cosmic (sky) noise}

For VHF and UHF radars, the galactic noise can be used as a source for absolute calibration. This concept was earlier used on a few occasions to convert received power into physical units (e.g., Hocking et al., 1983; Green et al., 1983; Inhester et al., 1990). Recently, the technique was extensively applied to the Resolute Bay radar by Swarnalingam and Hocking (2006) to absolutely calibrate the system as well as to estimate this radar's efficiency. The technique was also used to calibrate the McGill wind profiler radar, which makes measurements of rainfall. As a result of this, the McGill radar now records rainfall reflectivity measurements in this region within the accuracy of $1.5 \mathrm{~dB}$ error (Campos et al., 2007).

In this paper, we describe in detail the method as applied to the Resolute Bay VHF radar system. Although our aim here is to describe calibration work of the Resolute Bay radar system, we also discuss a generalized theory by taking into account the application of coherent integration, various pulse codings and also different receiver gain settings. Therefore, the theory provides a generalized equations for radar calibration so that it can be directly applied to any MST radar system. The advantage of this method is that it can be directly applied to any MST radar anywhere in the world as long as the cosmic noise variation above the site is known, which can be obtained from a suitable sky noise survey map. Since most of the sky surveys normally cover a larger geographical region of the earth, it will be possible to use the same sky noise survey map at multiple locations. This makes the calibration method ideal for the purpose of absolute comparisons of radar measurements at multiple locations, since the possible systematic errors associated with the absolute calibration would also be the same. (Following the calibration work at Resolute Bay by Swarnalingam and Hocking (2006, 2007), the method was also recently used by Kirkwood et al. (2007) to compare PMSE strengths at Kiruna $\left(68^{\circ} \mathrm{N}\right)$ and Wasa $\left(73^{\circ} \mathrm{S}\right)$ in Antarctica).

During PMSE experiments at Resolute Bay, the radar is normally alternatively selected to run in several different modes, such as Main-Mode, Quartet-Mode and TowerMode. In the following section, the absolute calibration procedure for the Main-Mode and Quartet-Mode radars are discussed, and the estimation of backscatter cross-section will be focused on the Main-Mode configuration. The MainMode antenna array consists a total of 128 two-element Yagi antennas. Its beam can point in five different directions in the sky with a narrow beam of one-way $2^{\circ}$ half-power-halfwidth (HPHW) (Hocking et al., 2001). On the other hand, the Quartet-Beam mode antenna array is relatively small in area, comprising only 4 two-element Yagi antennas at the corners of square with sides of $\lambda / 2$, embedded within the existing Main array. The Quartet-Mode beam points only in the vertical direction, and transmits and receives signals with a broad beam of $35^{\circ} \mathrm{HPHW}$. However, it is a simple system to handle, thus the losses are modest.

The first step in the calibration process is to determine the relationship between the input signal of the radar receiver and the corresponding recorded power in the storage unit of the radar system. Let us now consider a signal of voltage $u(t)$ at radar frequency $f$, which is a sinusoidal signal of 


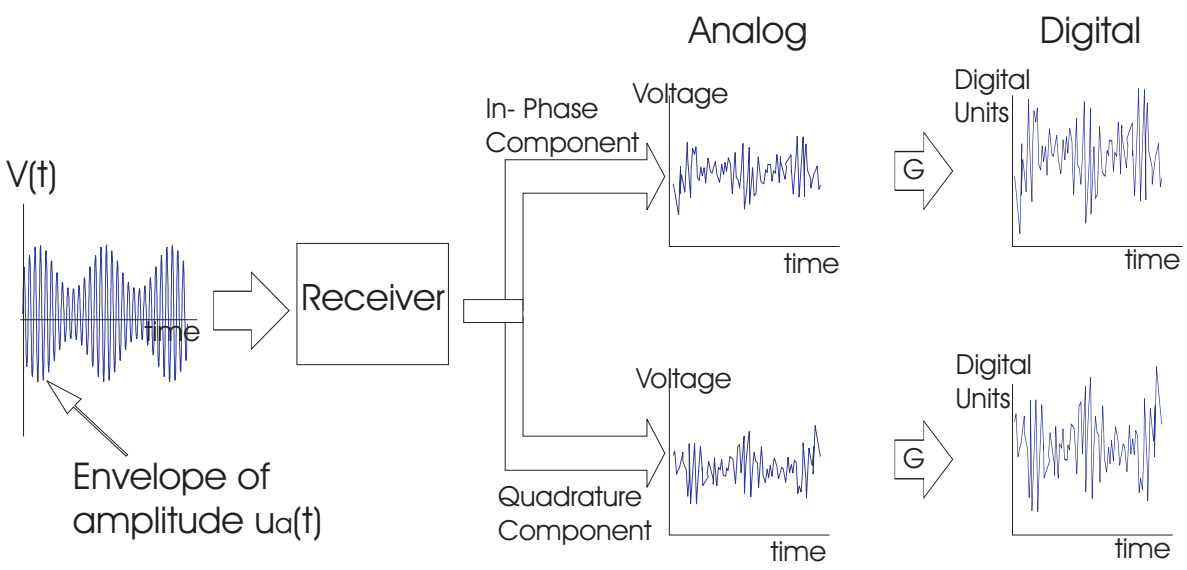

Fig. 1. A block diagram shows that a signal which is applied to the receiver as an input, goes through various stages before it becomes a spectrum. The input signal is first converted into in-phase and quadrature components in the receiver. The two components are then pre-amplified, and converted into digital form by the "system voltage gain".

frequency $f$ with an envelope of amplitude $u_{a}(t)$. Suppose it is fed into the receiver as shown in the Fig. 1, and then recorded in a storage file. For the moment, we assume that the input signal does not contain any pulse coding, and also no coherent integration process is applied in producing the final spectrum (this limitation will be generalized shortly). We further assume the receiver gain is set to its maximum available value. We now calculate the spectrum of this input signal and determine the standard deviation. At any instant of time, the relationship between the input and output signals of the radar receiver can be written as follows,

$$
\begin{aligned}
u_{o i}(t) & =G_{\mathrm{P}} \cdot u_{i}(t) \\
u_{o q}(t) & =G_{\mathrm{P}} \cdot u_{q}(t)
\end{aligned}
$$

where $u_{o}$ is the output signal. Indexes $i$ and $q$ refer to the in-phase and quadrature components of the input and output signals. The output signals (left-hand side) are in digital units while the input signals (right-hand side) are in Volts. The parameter $G_{\mathrm{P}}$ is the amplification factor, which is a constant value and has unit Volts ${ }^{-1}$. We will call this constant the "system voltage gain", and our first aim here is to determine this quantity $G_{\mathrm{P}}$ using random noise signal power (the index " $\mathrm{P}$ " is used to indicate that the receiver gain is set to its maximum available value).

Assume that random noise is now fed into the radar receiver. For a noise frequency $f_{j}$ of amplitude $u_{a j}$, suppose the in-phase component starts with the amplitude of $u_{a j}$ (when the phase is zero), passes through zero and then to a minimum of $\left(-u_{a j}\right)$. The signal will have a period of $T=\left(f_{j}-f_{o}\right)^{-1}$, where $f_{o}$ is the carrier frequency. Thus, the square of the standard deviation of in-phase component $\left(\sigma_{i j}^{2}\right)$ is given by,

$$
\sigma_{i j}^{2}=\frac{1}{\mathrm{~T}} \int_{0}^{\mathrm{T}} u_{a j}^{2} \cos ^{2}\left[2 \pi\left(f_{j}-f_{o}\right) t\right] d t=\frac{u_{a j}^{2}}{2}
$$

Likewise the quadrature component of the frequency $f_{j}$ will have a similar cycle, and hence the square of the standard deviation of quadrature component $\left(\sigma_{q j}^{2}\right)$ will be $u_{a j}^{2} / 2$.

At any instant of time, the vector addition of in-phase and quadrature contributes to produce the magnitude of the signal. Since all vectors rotate at different rates in the Argand diagram (they all have different frequencies), and since we sum over many cycles, we may add powers to produce the final power. Therefore, summing over all frequencies and ignoring the special case $f_{j}=f_{o}$ (which makes almost no contribution for a wide filter), and combining the above in-phase and quadrature components will lead to the following,

$$
\left(\sigma_{o i}^{2}+\sigma_{o q}^{2}\right)=G_{\mathrm{P}}^{2} \cdot\left(\sum_{j} u_{a j}^{2}\right)
$$

Since the quantity $\sum\left(u_{a j}^{2} / 2 R\right)$ is the averaged peak-input power of the input signal, where $R$ is the input impedance, the above relationship can be modified as follows in terms of energy units,

$$
\left(\sigma_{o i}^{2}+\sigma_{o q}^{2}\right)=2 G_{\mathrm{P}}^{2} R \cdot\left(\sum_{j} \frac{u_{a j}^{2}}{2 R}\right)
$$

A modification will be needed in the above Eq. (4), if pulse coding, coherent integrations and different receiver gain are applied. Let us now assume that the input signal contains a number $M$ of pulse code elements, the receiver gain is set to a value $A \mathrm{~dB}$, and an $\mathrm{N}$-point coherent integration is used during the signal processing. We also assume that we divide by $N$ and $M$ when we perform the coherent integrations (i.e. we use coherent averages) (Woodman and Guillen, 1974). In the case of noise signal, since the signal is uncorrelated from pulse to pulse the coherent averaging process would make the resultant amplitude proportional to $\sqrt{(N \cdot M)}$. This will 
Table 1. The selection of parameters for four noise generator experiments (upper portion of table) along with the calculated system voltage gain and receiver noise temperature values for the Resolute Bay radar (lower portion of table). Different values of pulse coding, coherent integration and filter widths are deliberately chosen in order to test the theory.

\begin{tabular}{lllll}
\hline Parameters & Noise Expt-1 & Noise Expt-2 & Noise Expt-3 & Noise Expt-4 \\
\hline PRF & $1200 \mathrm{~Hz}$ & $1200 \mathrm{~Hz}$ & $1200 \mathrm{~Hz}$ & $1200 \mathrm{~Hz}$ \\
Rx- Gain & $116 \mathrm{~dB}$ & $116 \mathrm{~dB}$ & $116 \mathrm{~dB}$ & $116 \mathrm{~dB}$ \\
Coh. Integration & 16 & 16 & 4 & 16 \\
Code & 8 -bit compli. & monopulse & monopulse & monopulse \\
Filter width (baseband) & $70 \mathrm{kHz}$ & $70 \mathrm{kHz}$ & $70 \mathrm{kHz}$ & $150 \mathrm{kHz}$ \\
Calculated $G_{\mathrm{P}}[$ au per Volts $]$ & $4.8494 \times 10^{9}$ & $4.8953 \times 10^{9}$ & $4.8307 \times 10^{9}$ & $4.8558 \times 10^{9}$ \\
Calculated $T_{\mathrm{RX}}[\mathrm{K}]$ & 800 & 884 & 821 & 866 \\
\hline
\end{tabular}

then be reduced by $(N \cdot M)$ when division takes place, thus the root mean square amplitude of the resultant signal will eventually be reduced by $\sqrt{(N \cdot M)}$. This means the above equation will take the form,

$$
\left(\sigma_{o i}^{2}+\sigma_{o q}^{2}\right)=\frac{2 G_{\mathrm{P}}^{2} R \cdot 10^{\frac{-X}{10}}}{N \cdot M \cdot L}\left\{\mathrm{P}_{\mathrm{N}}+\mathrm{N}_{\mathrm{R} X}\right\}
$$

where $\mathrm{P}_{\mathrm{N}}$ is the input noise power and the $\mathrm{N}_{\mathrm{R} X}$ is the noise power produced by the radar receiver (i.e. the equivalent power for the radar receiver noise temperature). The quantity $X$ refers to the difference between the maximum available receiver gain value and its current setting value $(X=P-A)$. On some occasions the coded pulses are considered as pairs (e.g. complementary code). In such situations, confusion may arise with the actual value of $M$. For example when complementary codes are used, each code will contain a pair of elements such that the second element is the complement of the first element (Schmidt et al., 1979). In such situations, the actual number of codes are two times $M$. Therefore, to avoid any confusion the parameter $L$ was introduced here, which corresponds to the number of elements of codes. $L$ will take a value 2 if complementary codes were used, otherwise it stays as 1 . With the availability of fast processing computers nowadays, a question may arise here as to whether applying coherent integration in a radar experiment is worthwhile or not. This was already discussed by Hocking (1997). However, here we allow for a general development, in which coherent integration and pulse coding may or may not be used, since some users still use this procedure. We also used limited coherent integration in our own experiments, but kept our spectral limits quite large (greater than $35 \mathrm{~Hz}$ ). Our generalized form of this calibration theory is also valid to apply without using coherent averaging procedures by simply assigning unity to the parameter $N$.

In the case of the Resolute Bay radar, the system voltage gain $G_{\mathrm{P}}$ was calculated using a commercially available noise generator. The noise signal from the noise generator, which can produce random noise, was fed directly into the receiver (bypassing the transmit-receive switch). The noise power that is fed into the radar receiver from the noise generator is given by $\mathrm{P}_{\mathrm{NG}}=(F+1) k \mathrm{~T}_{\mathrm{NG}} \Delta f_{\mathrm{RX}}$, where $F$ is a noise amplification factor, $k$ is Boltzmann's constant and $\mathrm{T}_{\mathrm{NG}}$ is the noise generator reference temperature and $\Delta f_{\mathrm{RX}}$ is the receiver band-pass filter width. By increasing the values of $F$, different noise powers were fed into the receiver, and the corresponding processed spectral powers were recorded. From a suitable regression plot of recorded power vs receiver input power, the system voltage gain $G_{\mathrm{P}}$ and also the receiver noise temperature $\left(\mathrm{T}_{\mathrm{RX}}\right)$ were determined. $G_{\mathrm{P}}$ is derived from the regression slope, and $\mathrm{T}_{\mathrm{RX}}$ from the offset.

In order to test the effects due to our application of coherent integration, pulse coding and filter widths, we deliberately setup four experiments with different choices of pulse types, pulse lengths (from monopulse to 8-bit complementary code), different choices of coherent averaging and also different values of filter widths. Table 1 shows the experimental parameters chosen in the four experiments. The calculated system voltage gain $\left(G_{\mathrm{P}}\right)$ and receiver noise temperature values $\left(T_{R X}\right)$ from these four experiments are also given in the lower part of the table. It can be seen from the table that the same $G_{\mathrm{P}}$ and $\mathrm{T}_{\mathrm{RX}}$ values were produced in all four experiments. This clearly proves the validity of our Eq. (5). In addition, $G_{\mathrm{P}}$ was also calculated using another calibration method, namely the "delay line calibration" (Latteck et al., 2008). In this method, an attenuated coherent signal was fed directly into the radar receiver and consequently $G_{\mathrm{P}}$ and $\mathrm{T}_{\mathrm{RX}}$ were calculated. Although the noise generation method does not include the losses due to imperfect signal generation or decoding on reception, the delay line method includes these losses. The comparison of these two methods shows a very good agreement, within an error of $2 \%$.

Equation (5) is only valid for noise signals. When the receiver receives coherent signals (as in the case of PMSE experiment), the effects due to pulse coding and coherent integration on the output power will be removed during the coherent averaging process. However, the different receiver gain settings must still be accommodated. The resultant equation in the case of coherent signal will thus be of the form, 
$\mathrm{P}_{\mathrm{Rec}}=2 G_{\mathrm{P}}^{2} \cdot R \cdot 10^{\frac{-X}{10}}\left\{\mathrm{P}_{\mathrm{N}}+\mathrm{N}_{\mathrm{R} X}\right\}$

where $\mathrm{P}_{\mathrm{Rec}}$ is the recorded power in the storage data file.

\subsection{Radar efficiency}

Once we know the system voltage gain of the radar system, our next aim is to estimate the overall system efficiency in signal reception. This can be achieved using available cosmic noise above the radar site. The cosmic noise, which is extraterrestrial in origin, is detected by the radar antenna array. It is then carried through a set of cables, and also through various devices, and finally reaches the receiver. Knowing the amount of the noise energy that is detected by the antenna array will allow us to estimate the system efficiency of the radar system. Let us assume a cosmic noise energy of P Sky $_{\text {S }}$ is detected by the antenna array at any instant of time, and out of this, an amount $\mathrm{P}_{\mathrm{RX}}$ reaches the receiver. Therefore the relationship between these two quantities can be written as follows,

$\mathrm{P}_{\mathrm{RX}}=e_{\mathrm{SYS}}^{R}\left\{\mathrm{P}_{\mathrm{Sky}}+\mathrm{N}_{\mathrm{Loc}}\right\}+\left(1-e_{\mathrm{SYS}}^{R}\right) \mathrm{N}_{\mathrm{Lin}}$

where the $e_{\mathrm{sYS}}^{R}$ refers to the system efficiency upon reception and $\mathrm{N}_{\mathrm{Loc}}$ refers to the noise power that originates in the surrounding area, partly due to Man-Made activities. $\mathrm{N}_{\mathrm{Lin}}$ refers to noise generated by the feed lines (cables). Along with sky noise, the noise $\mathrm{N}_{\mathrm{Loc}}$ is also picked up by the antenna array and reaches the receiver along with cosmic signals. The noise power contribution from this term is relatively high for the Resolute Bay radar site. However in contrast to sky noise, this local noise does not vary with time, and thus can be considered as a constant quantity throughout the day (this will be further discussed shortly). The noise power $P_{R X}$ is thus fed into the receiver, and will then be recorded in the computer as output signal. Therefore, the relationship between the input of receiver and the recorded power can be written as,

$$
\left(\sigma_{o i}^{2}+\sigma_{o q}^{2}\right)=\frac{2 G_{\mathrm{P}}^{2} R \cdot 10^{\frac{-X}{10}}}{N \cdot M \cdot L}\left\{\mathrm{P}_{\mathrm{RX}}+\mathrm{N}_{\mathrm{RX}}\right\}
$$

In combining Eqs. (7) and (8), we obtain the final calibration equation. It is convenient when dealing with noise power to express it in terms of equivalent temperature in Kelvin (dividing by $k \Delta f$ on both sides of the equation). Thus the final calibration equation can be rearranged in the following form,

$$
\mathrm{T}_{\mathrm{Rec}}=e_{\mathrm{SYS}}^{R}\left\{\mathrm{~T}_{\mathrm{Sky}}+\mathrm{T}_{\mathrm{Loc}}\right\}+\left(1-e_{\mathrm{SYS}}^{R}\right) \mathrm{T}_{\mathrm{Lin}}+\mathrm{T}_{\mathrm{RX}}
$$

where,

$$
\mathrm{T}_{\mathrm{R} e c}=\frac{\left(\sigma_{i}^{2}+\sigma_{q}^{2}\right)}{k \Delta f\left(\frac{2 G_{\mathrm{P}}^{2} R \cdot 10^{\frac{-X}{10}}}{N \cdot M \cdot L}\right)}
$$

Note that in the above equation, $\mathrm{T}_{\text {Sky }}$ refers to the equivalent sky noise temperature that falls into the antenna array. Knowing the amount of equivalent sky noise temperature and its variation with time in a typical sidereal day, allows us to determine $e_{\mathrm{sys}}^{R}$ by means of a suitable regression plot. While $\mathrm{T}_{\mathrm{Loc}}$ refers to the equivalent surrounding noise temperature in the close vicinity of radar site, $T_{\text {Lin }}$ is the ambient temperature of the surroundings, which is approximately $300 \mathrm{~K}$. The term $T_{R X}$ refers to the radar receiver noise temperature.

One of the crucial stages in this radar calibration method is the estimation of the equivalent sky noise temperature for the radar system. The calibration equations depend on the variation of the equivalent sky noise temperature in a typical sidereal day. Therefore, any error in the estimation of this value will significantly affect the estimation of the $e_{\text {sys }}^{R}$. The equivalent sky noise temperature variations over the Resolute Bay radar site were calculated from a recent sky survey at $22 \mathrm{MHz}$ by Roger et al. (1999). Another sky survey at $30 \mathrm{MHz}$, which is closer to our radar operational frequency, is also available which covers the entire Northern Hemisphere region (Cane, 1978). Nevertheless, this map cannot be used for the calibration work of Resolute Bay radar system, since the map's angular resolution is significantly lower than the width of our radar beam (especially the Main-Mode beam). Before using the sky survey at $22 \mathrm{MHz}$, the map values were converted into the equivalent temperatures at our radar frequency $(51.5 \mathrm{MHz})$ by assuming the cosmic radiation decreases with frequency by power law of mean spectral index $\beta$. It can be noticed elsewhere in the literature that the choice of $\beta$ actually ranges from 2.30 to 2.70 , especially for wider frequency bands from $13 \mathrm{MHz}$ to 1.4 GHz (e.g. Bridle, 1967; Sironi, 1974; Webster, 1974). In order to obtain the most accurate value for $\beta$, we have performed our own analysis and comparison, especially in the northern high latitudes region, by comparing five surveys within the frequency range $22-178 \mathrm{MHz}$ (Swarnalingam and Hocking, 2006; Swarnalingam, 2007). The five surveys that were used in our analysis were at $22 \mathrm{MHz}$ by Roger et al. (1999), $30 \mathrm{MHz}$ by Cane (1978), $45 \mathrm{MHz}$ by Campistron et al. (2001), $85 \mathrm{MHz}$ by Landecker and Wielebinski (1970) and $178 \mathrm{MHz}$ by Turtle and Baldwin (1962). Based on this comparison, it was found that the Roger et al. (1999)'s $22 \mathrm{MHz}$ survey maintains a $\beta$ value of 2.50 with respect to other surveys. The error is only $1 \%$ if the $30 \mathrm{MHz}$ survey is excluded, otherwise the possible error is about $5 \%$. Therefore, in our calibration work it was decided to use $\beta$ as 2.50 . Furthermore, our estimated value for $\beta$ is in good agreement with the $\beta$ used by Campistron et al. (2001) and Roger et al. (1999).

Figure 2a shows the converted sky noise temperature values at $51.5 \mathrm{MHz}$ for the entire Northern Hemisphere, and Fig. $2 b$ shows an example of the comparison of recorded diurnal sidereal noise variation with the actual sky noise temperature values in the case of the Main-Mode vertical beam (to be addressed shortly). For convenience Fig. 2a is plotted 


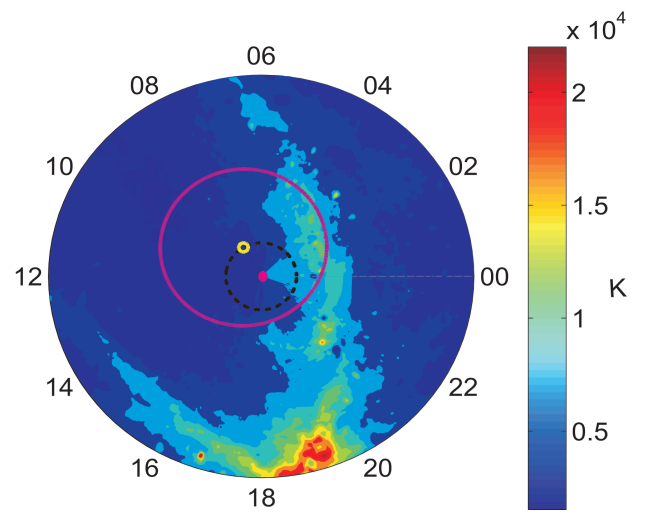

(a)

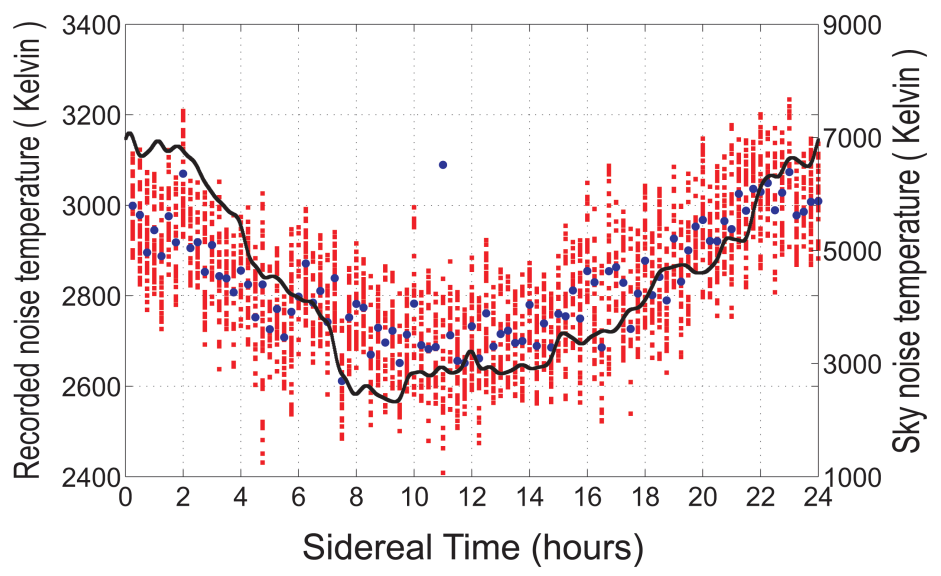

(b)

Fig. 2. (a) The sky noise at $51.5 \mathrm{MHz}$ for the entire Northern Hemisphere. The red dot at the center refers to the geographic north pole. The black dash-dash line in figure shows the path of the centroids of the Main-Mode vertical and Quartet beams across the celestial sphere in a sidereal day. While the Main beam covers a small cross-sectional area (yellow circle), the Quartet beam covers a larger cross-sectional area (magenta circle). See text for detail. (b) A comparison of 15 min averaged recorded sky noise (red dots) with the sky survey map values (black line) in the case of Main-Mode vertical beam. A total of 11 days in August 2001 were selected for the comparison, and the blue dots refer to the mean values in each time bin.

in right ascension - declination coordinates with the geographic north pole at the center (red dot). The black dashdash line shows the path of the centroids of the Resolute Bay Main-Mode and Quartet-Mode radar beams across the celestial sphere in a sidereal day. While the yellow circle refers to the projection of the Main-Mode vertical beam half power locus on the celestial sphere, the large magenta circle refers to the projection of the Quartet-Mode beam. It can also be noticed from the figure that the radar site will experience a lower level of sky noise during the sidereal day time, and higher level of noise during the sidereal night time.

A two-dimensional convolution process between the radar polar diagram and the equivalent sky noise temperature was carefully applied in order to calculate the sky noise temperature variations at the radar site. Since the Main-Mode radar beam (one-way HPHW of $2^{\circ}$ ) is much narrower than the Quartet-Mode radar beam (one-way HPHW of $35^{\circ}$ ), the estimated sky noise using the sky survey map shows variations of approximately $2500-6500 \mathrm{~K}$ (minimum to maximum) in the Main-Mode and 4300-5700 K in the Quartet-Mode, respectively. We also need to consider possible ionospheric absorption. Since, a large data set was available for Resolute Bay, it was possible to identify the quiet day noise variations from this data set, and only noise data from those days were used in the estimation of $e_{\text {sys. }}^{R}$. Figure 2b shows an example of the comparison of diurnal sidereal noise variation of the recorded noise (red squares) with the actual sky noise temperature values (black solid line) for the Main-Mode vertical beam. The recorded noise are $15 \mathrm{~min}$ averaged values. The mean values of each time bin have been marked by blue dots. A total of 11 days during August 2001 were used in this plot.

In order to calculate the efficiency, we capitalize on the diurnal variation of the actual sky noise and the diurnal variation of recorded noise. Comparison of the peak-to-peak variation in this way bypasses contributions of extra constantnoise contributions. The linear regression fitting between these two is shown in Fig. 3. While part (a) corresponds to the Main-Mode radar, part (b) shows the corresponding fit for the Quartet-Mode radar. In order to get a best line fit, a "robust" linear fitting method was adopted. Unlike the least square method which takes into account all the data points, the "robust" fitting method will omit the most deviated data points, and will calculate the slope based on how the majority of the data points behave (Maronna et al., 2006). However, the omitted data were less than $1 \%$ in our case. It was found that the mean efficiency of the Main-Mode is $12 \% \pm 3 \%$ whereas the mean efficiency of Quartet-Mode is about $59 \% \pm 3 \%$.

While the simple Quartet-Mode radar has a reasonably good efficiency, the more complex Main-Mode has a low efficiency. However, these values are consistent with our expectations. At Resolute Bay, although the mean receiver noise temperature is $843 \mathrm{~K}$, the level of local noise $\left(\mathrm{T}_{\mathrm{Loc}}\right)$ is significantly higher. As mentioned earlier, although there may be various sources of local noise, it is believed that the major portion of $\mathrm{T}_{\mathrm{Loc}}$ is produced within the radar building itself. In addition to accommodating the radar transmitter and the receiver, the building contains several other 


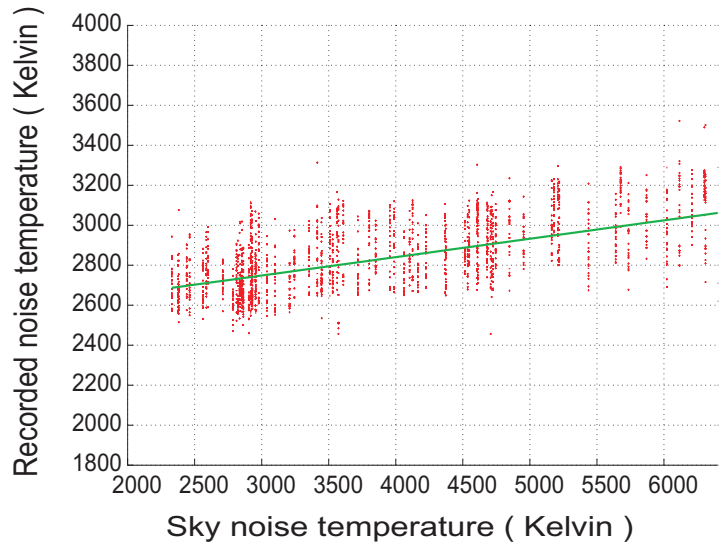

(a)

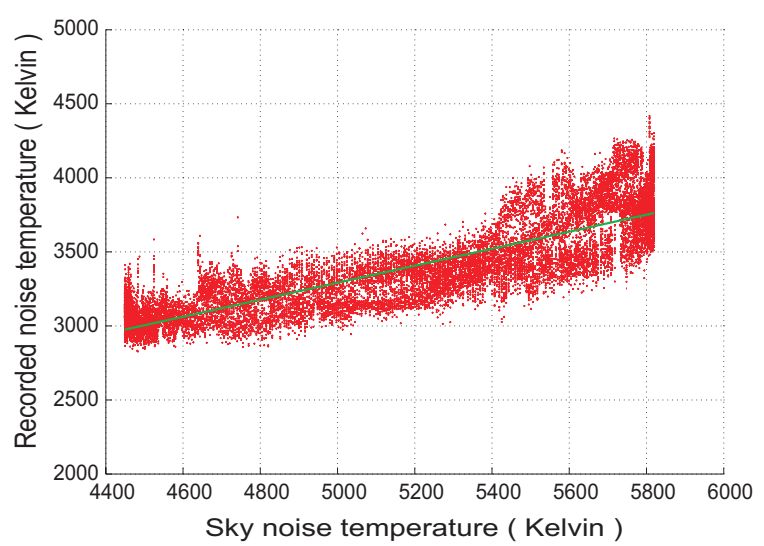

(b)

Fig. 3. The linear regression fit between the recorded sky noise temperature values and the actual sky noise values for a sidereal day in the case of the Resolute Bay radar. While (a) corresponds the Main-Mode radar, part (b) corresponds to the Quartet-Mode. In order to get a best line fit, a robust linear fitting method was adopted.

instruments, including several all-sky cameras and multiple UPS's (Uninterrupted Power Supply). We found that the cameras and other related equipment radiate a significant level of noise power to the surroundings. Unfortunately, the building itself cannot be grounded, due to deep permafrost. The radiated noise from the radar building is then picked up by the antenna array and also possibly by the set of long cables. We have confirmed the above fact by comparing the noise levels in summer with winter seasons. While the radar is continuously operated throughout the year, some other onsite optical equipment is only operated during the winter season. We have noticed that the noise level in the close vicinity of the site is further increased by over $10 \mathrm{~dB}$ once this optical equipment has been turned on, and the noise level goes back to its initial level after they have been turned off during summer. However, not all equipment is turned off in summer, and the residual noise is still quite high.

As described above, almost all the equipment which is operated during summer at Resolute Bay, run continuously for twenty four hours in a day. Our long term careful monitoring of noise level clearly indicates that this equipment produces constant-noise as a function of time of day in the surroundings. This is especially true when we consider collecting noise over several sidereal days.

\subsection{Losses in sub-component devices}

The Main-Mode radar's antenna array is a considerable distance from the radar building (transmit-receive building), and the antennas are connected by long cables. This makes for a significant amount of loss when signals travel from the antenna array to the radar receiver building and vice versa. The antenna array, which comprises a total of 128 antennas, is arranged in groups of quartets, and each quartet is fed by a long cable. Therefore, a total of 32 long cables are used to feed the antenna array from the transmit-receive building. Cables typically have lengths of $100-150 \mathrm{~m}$, although all are cut to exact integral numbers of half-wavelengths. There are two types of cables used to connect the antenna array with the transmit-receive building. One type is low-loss Andrew 1/2-inch Heliax cable and the other type is higher-loss Belden 9913 cable (Hocking et al., 2001). While the first cable type has a loss factor of $0.5 \mathrm{~dB}$ per $30 \mathrm{~m}$, the second type has a loss factor of $0.9 \mathrm{~dB}$ per $30 \mathrm{~m}$. The corresponding loss for the full length of Andrew 1/2-inch Heliax cable is about $2.5 \mathrm{~dB}$, and the corresponding loss for the full length of 9913 is $4.5 \mathrm{~dB}$. However, at Resolute Bay, the total length of each cable is comprised of a selection of both types of cable. This is organized in such a way that the percentage of 9913 would increase from the center of the array to the outer array. This taper helps to suppress sidelobes of the polar diagram. The procedure is analogous to application of a window when applying Fourier transform in signal analysis. Some power is lost, but the benefits of reduction of noise and spurious harmonics are improved. A similar setup was also used with Mobile SOUSY VHF radar by Czechowsky et al. (1993) (also see Dolph, 1946). Based on this arrangement, the average loss in the cable is $3.5 \mathrm{~dB}$ with higher attenuation at the edges and less in the middle.

Note the efficiency values of both radars calculated in the previous section include all the losses; not only the antenna and the transmission lines, but also other sub-components such as beam pointing units, matching units (T-R distribution unit) and transmit-receiver switch (T-R switch). We have carried out efficiency tests in these devices. Our tests for the combined matching and beam pointing units revealed a loss of $2.2 \mathrm{~dB}$ in reception. The matching unit is the component 
that matches the antenna array with the transmitter and receiver units in terms of impedances. During a radar experiment, when a signal is transmitted, power from the transmitter must be distributed to all antennas with minimal loss. Likewise, during reception the received signals from all antennas must be collected effectively and fed into the receiver. Our matching unit achieves these goals. A similar but slightly different design of matching unit has been used for the McGill wind profiler radar, which was installed after the Resolute Bay radar installation (Campos et al., 2007). Tests on both McGill and Resolute Bay show similar (low) losses in the distribution unit (Swarnalingam, 2007). This indicates that the existing matching unit at Resolute Bay does not have any unusual amount of loss. Losses also occur in the T-R switch. These are measured to be $1.5 \mathrm{~dB}$.

In the case of the Main-Mode radar, system efficiency calculations show that the radar has total loss of $9 \mathrm{~dB}$ in reception. In this total loss, $3.5 \mathrm{~dB}$ loss takes place in the transmission lines, $2.2 \mathrm{~dB}$ loss takes place in matching and beam pointing units, and another $1.5 \mathrm{~dB}$ loss takes place in the T$\mathrm{R}$ switch. On the other hand, the Quartet-Mode is a simple radar system, and it does not contain either of the above mentioned matching unit or beam pointing units. The major losses in this system are due to transmission lines (in this case, 7/8-inch Heliax) and T-R switch, which together is about $2.5 \mathrm{~dB}$.

Since the Resolute Bay radar is located in extreme weather conditions, great care has been taken to ensure that it has been properly maintained from the time of its installation. Over the years, measurements of transmitting power, tests for impedance matching, and tests for losses in connectors have been performed almost in every year during our routine visits to the radar site. Noise level is monitored on a continuous basis. Measurements for impedance are made for all antennas on all visits. The impedance value for each quartet is maintained at $\left(Z=50 \pm 4 \Omega, \Phi=0^{\circ} \pm 5^{\circ}\right)$. These values have been consistent since 1997 .

\section{Calibrated PMSE signal strength at Resolute Bay}

Absolute calibration and the calculation of radar efficiency have provided a way to determine PMSE strength at Resolute Bay. The received PMSE powers $P_{R}$ in Watts were calculated using the estimated $G_{\mathrm{P}}$ value. PMSE backscatter cross-section is then calculated. The radar backscattered power is given by,

$$
\begin{aligned}
P_{R}= & \frac{P_{T} e_{\mathrm{sys}}^{T} e_{\mathrm{sys}}^{R} \sigma \Delta R}{(4 \pi)^{2} h^{4}} . \\
& \int_{\theta=0}^{\frac{\pi}{2}} \int_{\phi=0}^{2 \pi} G_{T}(\theta, \phi) A_{R}(\theta, \phi) h^{2} \sin (\theta) d \theta d \phi
\end{aligned}
$$

where $P_{T}$ is the transmitted peak power, $e_{\text {sys }}^{T}$ is the system efficiency in transmission, $e_{\mathrm{sys}}^{R}$ is the system efficiency in reception, $h$ is the echo backscatter height, and $\Delta R$ is the vertical range resolution, $G_{T}(\theta, \phi)$ is the antenna gain in transmission and $A_{R}(\theta, \phi)$ is the antenna effective area in reception. In the above equation, backscatter cross-section is denoted as $\sigma$, which is the return power per unit volume, per unit solid angle, for each unit of incident power from the ground. Since a radar like Resolute Bay uses a very narrow beam for transmission and reception, and also both polar diagrams are axially symmetric and phased such that their maxima point in the same direction, the above integral can be safely approximated to the following form (see Hocking, 1985),

$P_{R}=\frac{P_{T} e_{\mathrm{sys}}^{T} e_{\mathrm{sys}}^{R} \sigma G_{T M} A_{R M}}{(4 \pi)^{2} h^{4}} \cdot\left[\frac{\pi\left(h \theta_{\frac{1}{2}}^{1}\right)^{2} \Delta R}{2 \ln 2}\right]$

where $G_{T M}$ and $A_{R M}$ are the antenna gain and effective area respectively in the direction of pointing. $\theta_{\frac{1}{2}}^{1}$ is one-way HPHW. Our main aim here is to estimate the PMSE backscatter cross-section. It is normally denoted by $\eta$, which is defined as the total power that would be scattered by a unit volume of scatterers if the power was scattered isotropically with the same intensity equal to that of $\sigma$ per unit solid angle and per unit incident power. The relationship between $\eta$ and $\sigma$ is given by $\eta=4 \pi \sigma$. Furthermore, $G_{T M}$ and $A_{R M}$ can be linked by $G_{T M}=A_{R M} \cdot 4 \pi / \lambda^{2}$, where $\lambda$ is the radar wavelength. Therefore, from the above Eq. (11) the backscatter cross-section, $\eta$ can be written as,

$$
\eta=\frac{128 \pi^{2}(2 \ln 2) h^{2} P_{R}}{\left(G_{T M}\right)^{2} \lambda^{2} e_{T} e_{R} P_{T}\left(\theta_{\frac{1}{2}}^{1}\right)^{2}(2 \cdot \Delta R)}
$$

Table 2 summarizes the values that have been used in this study for above parameters. In addition to our careful calibration work, two other parameters, the antenna gain $\left(G_{T M}\right)$ and system efficiency in transmission $\left(e_{\mathrm{sys}}^{T}\right)$, must also be calculated properly for the accurate estimation of PMSE backscatter cross-section. The antenna gain was carefully calculated as $24 \mathrm{~dB}$ using a simulation model, which replicated the exact antenna array structure with two-element Yagi antennas. The calculated antenna gain value shows a very good agreement with independent calculations using the Numerical Electromagnetics Code (NEC) (Latteck et al., 2008). Note that the second term in Eq. (11) refers to the effective radar volume, and it is valid for narrow and moderate beam width radars. To verify this, we have also carried out the full integral associated with the Eq. (10), and found that the results of Eq. (10) and Eq. (11) are consistent (Hocking and Vincent, 1982).

The true PMSE powers were determined by removing the background noise from the recorded backscattered power. As mentioned earlier, not only are PMSE powers normally weak at Resolute Bay, but also the background noise level is high, therefore it is important to remove the background noise from the returned signal power. 

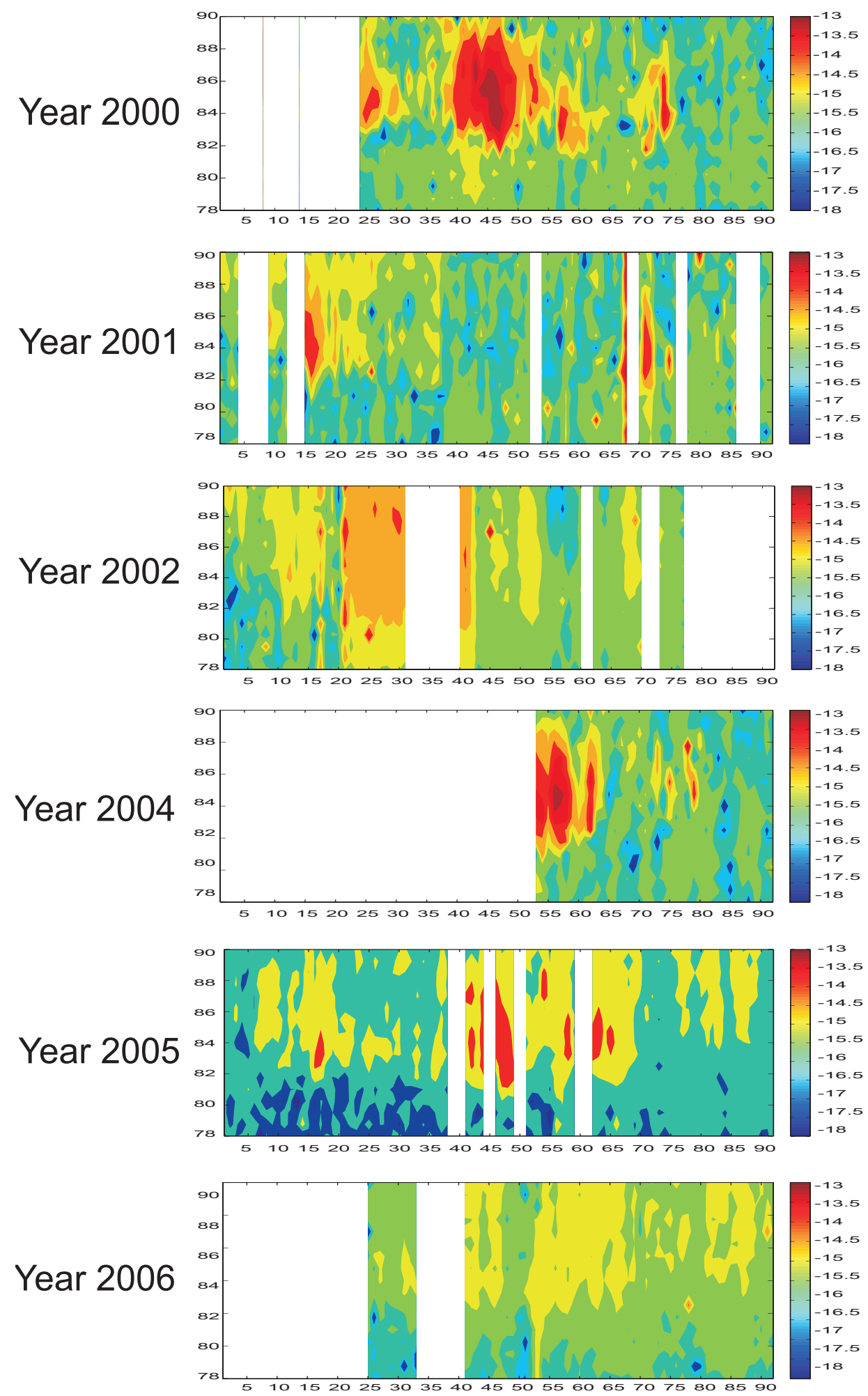

Days

Fig. 4. Long term PMSE seasonal variation observed at Resolute Bay for the interval year 2000-2006 (except 2003). For each year, data for the months June, July and August are shown. The daily mean backscatter cross-section values are plotted using natural logarithmic scale for height region $80-90 \mathrm{~km}$. The gaps refer to missing data. 
Table 2. Summary of the operational parameters for the Resolute Bay radar, applied during PMSE experiments as well as backscatter cross-section estimations.

\begin{tabular}{ll}
\hline $\begin{array}{l}\text { The operational parameters for the Reso- } \\
\text { lute Bay radar during PMSE experiments } \\
(1997-2006)\end{array}$ \\
\hline Frequency & \\
Transmitter Peak Power & $51.5 \mathrm{MHz}$ \\
$\Delta R$ & $12 \mathrm{~kW}$ \\
PRF & $750 \mathrm{~m}$ \\
HPHW (one-way) & $1200 \mathrm{~Hz}$ \\
Code & $2^{\circ}$ \\
$G_{T M}$ & $8-\mathrm{bit} \mathrm{compli}$. \\
$G_{R M}$ & $24 \mathrm{~dB}$ \\
$e_{\text {sys }}^{T}$ & $24 \mathrm{~dB}$ \\
$e_{\text {sys }}^{R}$ & $35 \%$ \\
Coherent Integration & $12 \%$ \\
Filter Width (baseband) & $16-\mathrm{point}$ \\
Average minimum deductable back scat- & $8.8 \times 10^{-16} \mathrm{~m}^{-1}$ \\
ter cross-section & \\
\hline
\end{tabular}

\subsection{Long term seasonal variations}

During the first few years of its operation, the Resolute Bay radar observed PMSE on a selective basis, being run for a few days or weeks at a time in a campaign type mode. A continuous mode of PMSE observation was started from the year 2000. The PMSE season at Resolute Bay starts typically in early/mid June and then ends sometime in early/mid August. As observed in other locations, at Resolute Bay also the echoes go to their highest strength of activities in middle of July. The long term seasonal study reveals an important fact, in that the PMSE strength at this location is not consistent from year to year. That is, their strengths showed a great level of variability from one year to another. This fact can be clearly seen from Fig. 4, in which the seasonal variation of the backscatter cross-section values are shown for the interval year 2000-2006 (except 2003). In this contour plot, daily averaged PMSE backscattered power for the months June, July and August for each year were used. It can be seen from the figure that the echoes were strong in July 2000, July 2004 and July 2005, and significantly weaker in years 2001, 2002 and 2006. Unfortunately, due to unavoidable technical difficulty, the data for the year 2003, and also for June 2004 are not available.

Similar inter-annual variability was also reported with $50 \mathrm{MHz}$ SOUSY radar at Svalbard by Sarango and Woodman (2003) at least for the interval year 1999-2001. On the other hand, the 53.5 MHz ALWIN radar at Andenes has observed much less significant inter-annual variability (Bremer et al., 2006). For example at Andenes in 1999-2005, the PMSE occurrence rates in July remained near $80-90 \%$ in each year with an exception in 2002, in which slightly lower occurrence rates appeared (see Fig. 5 in Bremer et al., 2006). In contrast to this, the PMSE occurrence rates at Resolute Bay were not consistent from one year to another. In years 2000, 2004 and 2005, they appeared with an occurrence rates up to 60-80\% during July. But in years 2001, 2002 and 2006, they showed much significantly lower occurrence rates (30-40\%) during July.

Figure 4 also indicates that the PMSE season at Resolute Bay is relatively short compared with other locations. In other locations, the PMSE season normally starts in late May or early June and lasts until the end of August or early September (see Fig. 6 in Bremer et al., 2006). However, the Resolute Bay radar is operated with $12 \mathrm{~kW}$ transmitter, which is significantly less power compared with the transmitter powers used by the above mentioned two radars. In addition, the site experiences high level local noise. Therefore, we cannot rule out the fact that these two constraints make the radar unable to detect weak PMSE echoes, especially in the early and later parts of the season. Note that these constraints however will not cause any problem in detecting strong PMSE echoes. As we will see shortly, the PMSE strength remains significantly low at this site even after considering these facts.

Long term seasonal studies also revealed an unusual activity that took place between the late June and the early July in 2002. During this period, the radar recorded backscattered power covering a broader depth of height, from $75 \mathrm{~km}$ to its maximum range up to $93.5 \mathrm{~km}$, with moderate echo strength. This was an unusual event to observe at Resolute Bay (see panel three in Fig. 4).

\subsection{Backscatter cross-section distributions}

During the last decade, PMSE were strong at Resolute Bay only for three seasons, namely the years 2000, 2004 and 2005 (2003 unknown). Fig. 5 shows the backscatter distributions for the month of July in these three seasons. The upper panel shows logarithmic histograms for the estimated backscatter cross-sections for the month of July in 2000. The middle and lower panels show the same for July 2004 and July 2005, respectively. In this study, the maximum power for each $15 \mathrm{~min}$ bin size was first identified, and these values were then used in the estimation of backscatter distribution. The estimated values for these three years ranges from $10^{-16}$ to $10^{-12} \mathrm{~m}^{-1}$, though the number of occurrences for these two extreme values were very low. The red solid lines refer to the median values of each distribution, and the dash-dash lines refer to the geometric mean values. It was found that the median values were $4.53 \times 10^{-15} \mathrm{~m}^{-1}$ for July $2000,1.07 \times 10^{-14} \mathrm{~m}^{-1}$ for July 2004 and $2.63 \times 10^{-15} \mathrm{~m}^{-1}$ for July 2005 . The corresponding geometric mean values for these years were $6.33 \times 10^{-15} \mathrm{~m}^{-1}, 1.20 \times 10^{-14} \mathrm{~m}^{-1}$ and $4.01 \times 10^{-15} \mathrm{~m}^{-1}$, respectively. These calculated median values are relatively lower (up to an order of magnitude) 

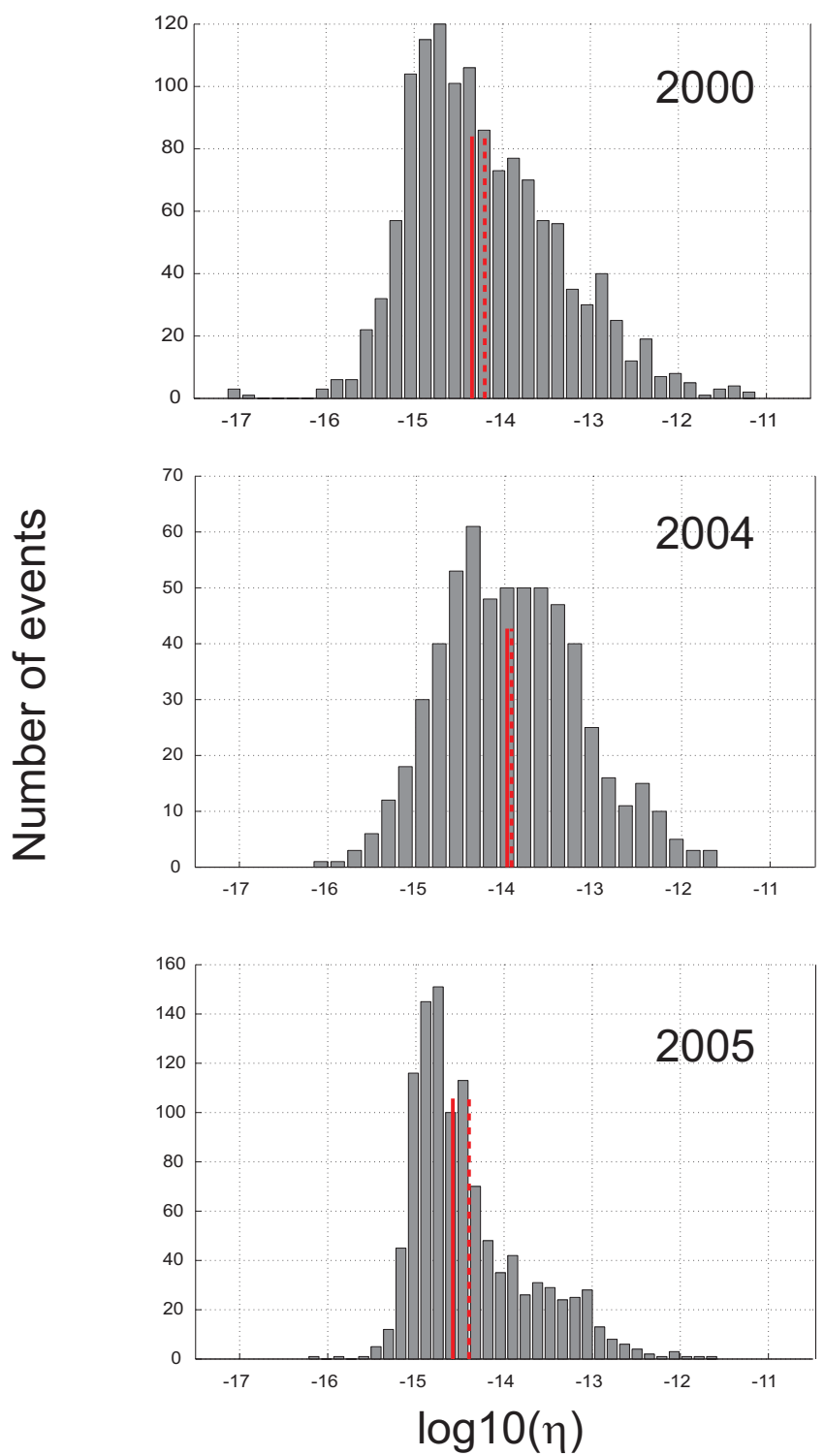

Fig. 5. A comparison of logarithmic histograms for the estimated PMSE backscatter cross-sections for the month of July in 2000 (upper panel), 2004 (middle panel) and 2005 (lower panel). PMSE strengths at Resolute Bay were strong during these three years. The solid and dash-dash lines refer to the distribution median and geometric mean, respectively. The number of events is counted in every fifteen minutes interval. (In July 2004, the radar was operated only for ten days.)

compared with backscatter cross-section values calculated at SOUSY Svalbard radar and at ALWIN Andenes radar (Röttger, 2001; Latteck et al., 2008).

In order to investigate the variation of PMSE strength properly at Resolute Bay, distributions of backscatter crosssection were estimated for each month. In this study the observed maximum power for each $15 \mathrm{~min}$ time bin was consid-
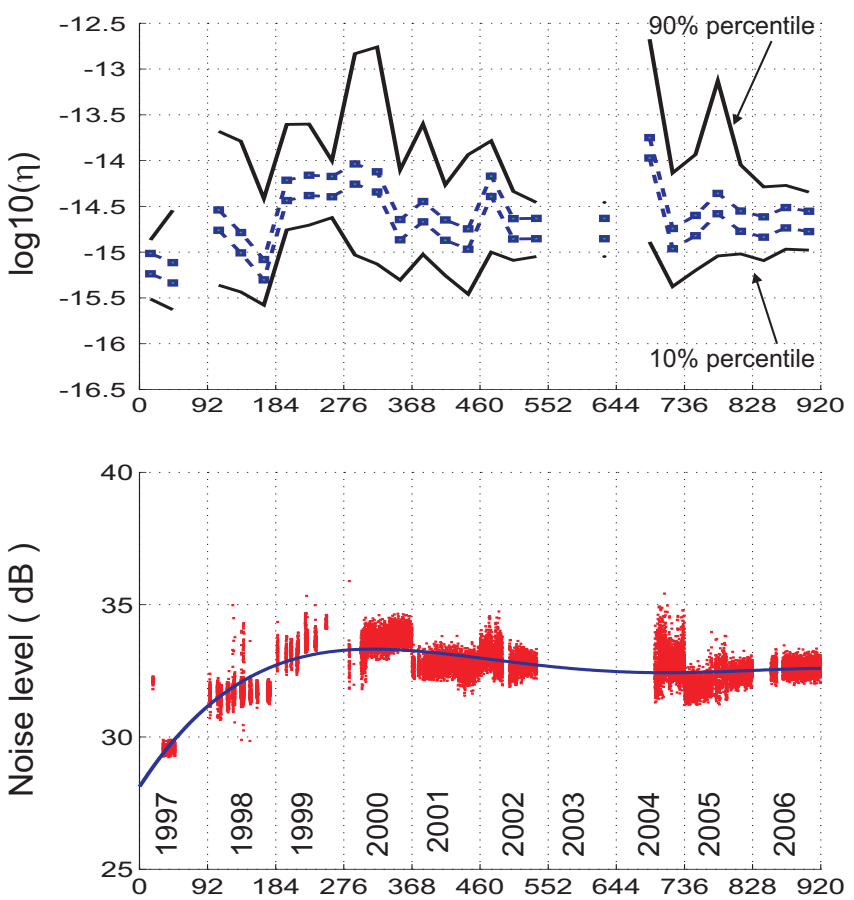

Days (counted from June to August only)

Fig. 6. The recorded backscatter cross-section values for a period of ten years at Resolute Bay (upper panel). The two dash-dash lines show the calculated medians of two backscatter cross-section distributions based on the lowest and highest system efficiency values. The two solid black lines refer to the 90th and 10th percentile values of the two distributions. The lower panel shows the noise variations at the radar site. The days are counted from 1 June to 31 August each year. The gaps refer to missing data.

ered. The results are shown in Fig. 6, where the upper panel shows the calculated logarithmic backscatter cross-section values. The two blue dash-dash lines refer to the variation of the backscatter cross-section medians over the years at Resolute Bay. The purpose of the two lines is to show the possible errors with the estimation of the medians. These two lines show the range of the median values due to the possible errors in our radar calibrations and calculations of the efficiency of the system on reception $\left(e_{\mathrm{sys}}^{R}\right)$. It was found that the lowest and highest possible values of $e_{\text {sys }}^{R}$ for the vertical beam were $9 \%$ and $15 \%$ respectively. Therefore, the two blue dash-dash lines refer to the median values based on these two efficiency values. The two black solid lines refer to the 90th and 10th percentile values for the distributions. The upper black line refers to the 90th percentile values based on the lowest efficiency value, while the lower black line refers to the 10th percentile values based on the highest efficiency value. From the figure, we cannot see any indication for systematic increase or decrease in PMSE median strengths at Resolute Bay. However, in regards to the strength of echoes 
we see the greatest variability. The histograms show a great level of variability in the high power tail of the distribution over the years.

The lower panel refers to the mean noise variation at the site. Over the years, the PMSE experimental configurations such as number of coherent integration, pulse coding and filter widths have not been changed, thus this plot is a good source to study the noise variations at the site vicinity. A $3 \mathrm{~dB}$ increased in noise level can be seen during the period 1997-1999. This happened as a result of installation of other experimental devices at the site. A slight increase in noise level during 2004 is a result of our various tests that were performed during the calibration work.

\section{Discussion}

In our Resolute Bay Main-Mode backscatter cross-section calculations, we have carefully avoided any underestimations in PMSE backscatter cross-sections. For example, using a higher system efficiency values $\left(e_{\text {sys }}^{T}\right.$ or $\left.e_{\text {sys }}^{R}\right)$ or higher antenna gain value $\left(G_{T M}\right)$ would result in lower values of backscatter cross-section than that calculated here. In our estimation, we have taken into account all possible losses, and used the lowest possible values for above parameters. The estimated values are still lower than other radars, especially Svalbard SOUSY radar and Andenes ALWIN radar.

Another potential issue for the possible underestimation of backscatter cross-section is aspect sensitivity of PMSE scatterers. The backscatter Eq. (12) assumes scattering is isotropic, which may not be always true with PMSE, since they have shown aspect sensitivity on some occasions. If the scatterers are anisotropic then the power received by the radar is the integration over the combined beam of polar diagram of radar and scatterers (e.g. Röttger, 1981; Hocking, 1986). In such scenarios, the effective two-way HPHW can be shown as,

$\sin ^{-2}\left(\theta_{\text {eff } \frac{1}{2}}^{\mathrm{T}}\right)=\sin ^{-2}\left(\theta_{\frac{1}{2}}^{\mathrm{T}}\right)+\sin ^{-2}\left(\theta_{s \frac{1}{2}}\right)$

where $\theta_{s \frac{1}{2}}$ is HPHW of the backscatter polar diagram of the scatterers, $\theta_{\frac{1}{2}}^{\mathrm{T}}$ is two-way HPHW of radar and $\theta_{\text {eff } \frac{1}{2}}^{\mathrm{T}}$ is the effective HPHW of the combined two-way polar diagram (Hocking, 1987). Thus, for example if the PMSE scatterers at Resolute Bay have an aspect sensitivity angle in the range of $\theta_{s \frac{1}{2}}=10^{\circ}-20^{\circ}$ and the two-way HPHW of the Main-Mode $\theta_{\frac{1}{2}}^{\mathrm{T}}=1.4^{\circ}$, then the effective combined beam width $\left(\theta_{\mathrm{eff} \frac{1}{2}}^{\mathrm{T}}\right)$ will only be in the range of $1.39^{\circ}-1.40^{\circ}$. As we see, this is very close to the actual Main-Mode's two-way HPHW, thus would not affect our backscatter estimations by any significant amount. Even if PMSE scatterers occurred with a very high aspect sensitivity angle of $5^{\circ}, \theta_{\text {eff } \frac{1}{2}}^{\mathrm{T}}$ will be $1.36^{\circ}$, which would only affect our estimated backscatter cross-sections by $0.3 \mathrm{~dB}$.
The Resolute Bay radar, which has been the only radar in the north american sector to monitor PMSE continuously over the years, is also located close to both the magnetic north pole $\left(82.7^{\circ} \mathrm{N}, 114.4^{\circ} \mathrm{W}\right)$ and geomagnetic north pole $\left(79.7^{\circ} \mathrm{N}, 71.8^{\circ} \mathrm{W}\right)$. Thus its location remains a true polar cap site for both the lowest and highest $K_{p}$ index values. It was recently argued by Morris et al. (2005) that PMSE are influenced by electron precipitation, which is more prevalent in the auroral oval region compared with inner region. The above concept was recently verified by using a new $51.0 \mathrm{MHz}$ VHF radar at Eureka $\left(80^{\circ} \mathrm{N}, 86^{\circ} \mathrm{W}\right)$ in northern Canada. This new radar was installed during summer 2007. The radar is operated at $51.0 \mathrm{MHz}$ with a transmitter peak power of $36 \mathrm{~kW}$, which is three times higher than that of Resolute Bay. As for Resolute Bay, the radar has five multiple narrow beams (one-way HPHW of $2.75^{\circ}$ ), comprising an array of 128 three-element Yagi antennas. Due to logistical reasons, and the fact that the Eureka radar has its own building, the efficiency of this radar is much better than Resolute Bay. Furthermore, the local noise is negligible. This new polar cap radar started its operation for PMSE observation from late July 2007. The initial PMSE observations reveal that PMSE strengths at Eureka are comparable with at Resolute Bay, but still weak compared with Svalbard and Andenes. The radar was operated in PMSE mode continuously during 1-31 August 2007. PMSE appeared almost everyday during the first 10-12 days. Subsequently, their strengths started to decrease gradually, and finally they completely disappeared before the end of August. We have calibrated the Eureka VHF radar also by applying the same method that was used at Resolute Bay. We then calculated PMSE backscatter crosssection using the data collected during 1-10 August 2007. We found that the median of backscatter cross-section as $7.77 \times 10^{-15} \mathrm{~m}^{-1}$. Furthermore, simultaneous PMSE observations at Resolute Bay and Eureka were conducted during June-July 2008 (Swarnalingam et al., 2008). The median values of the calculated backscatter cross-section distributions for Resolute Bay and Eureka were $4.55 \times 10^{-15} \mathrm{~m}^{-1}$ and $2.69 \times 10^{-15} \mathrm{~m}^{-1}$ respectively during June 2008 , and $5.36 \times 10^{-15} \mathrm{~m}^{-1}$ and $3.61 \times 10^{-15} \mathrm{~m}^{-1}$ respectively during July 2008. These values clearly show that PMSE strengths from these two sites are comparable, and both significantly weaker than for the Svalbard SOUSY radar and Andenes ALWIN radar. Our results are further supported by the recent satellite observations of polar mesospheric clouds (PMC), which are generally believed to have strong links with PMSE, conducted by Thomas et al. (2008). These authors have also noticed a clear longitudinal variation in the strength of PMC, especially in the northern arctic region.

\section{Conclusions}

We have presented a technique for absolute radar calibration using cosmic noise variations. The significant advantage 
of this generalized method is that it can be applied directly to any MST radar anywhere in the world to determine the radar efficiency. Absolute calibration of the Resolute Bay VHF radar system has allowed us to investigate decadelong PMSE activity at this location in terms of absolute signal strengths. The long term study clearly shows that the strength of PMSE shows considerable inter-annual variability. It has been found that generally the median backscatter cross-section of the distribution remains relatively unchanged from year to year (with modest exceptions in July 1997, August 1998 and July 2004), but a great level of variability occurred in their highest backscatter cross-section values. On average the median of the backscatter cross-section appears in the order of $10^{-15} \mathrm{~m}^{-1}$. This is an order of magnitude lower compared with values at other high latitude radars observed with the same frequency.

Acknowledgements. The authors thank to Tom Landecker, (from the Dominion Radio Astrophysical Observatory in Penticton, Canada), Martin Friedrich (from the Department of Communications and Wave Propagation, Graz University of Technology, Austria) and Bernard Campistron (from the Aeronomy Laboratory at the Midi-Pyrenees Observatory, Université Paul Sabatier, France) for providing sky survey data.

Topical Editor U.-P. Hoppe thanks two anonymous referees for their help in evaluating this paper.

\section{References}

Bremer, J., Hoffmann, P., Latteck, R., and Singer, W.: Long-term changes of mesospheric summer echoes at polar and middle latitudes, J. Atmos. Terr. Phys., 68, 1940-1951, 2006.

Bridle, A. H.: The spectrum of the radio background between 13 and 404 MHz, Mon. Not. R. Astr. Soc., 136, 219-240, 1967.

Campistron, B., Despaux, G., Lothon, M., Klaus, V., Pointin, Y., and Mauprivez, M.: A partial $45 \mathrm{MHz}$ sky temperature map obtained from the observations of five ST radars, Ann. Geophys., 19, 863-871, 2001, http://www.ann-geophys.net/19/863/2001/.

Campos, E. F., Hocking, W. K., and Fabry, F.: Precipitation measurement using VHF wind-profiler radars: A multifaceted approach to calibrate radar antenna and receiver chain, Radio Sci., 42, RS3003, doi:10.1029/2006RS003508, 2007.

Cane, H. V.: A $30 \mathrm{MHz}$ map of the whole sky, Aust. J. Phys., 31, 561-565, 1978.

Cho, J. Y. N. and Kelley, M. C.: Polar mesosphere summer radar echoes: Observations and current theories, Rev. Geophys., 31, 243-265, 1993

Cho, J. Y. N. and Röttger, J.: An updated review of polar mesosphere summer echoes: Observation, theory, and their relationship to noctilucent clouds and subvisible aerosols, J. Geophys. Res., 102, 2001-2020, 1997.

Cho, J. Y. N., Hall, T. M., and Kelley, M. C.: On the role of charged aerosols in the polar mesosphere summer echoes, J. Geophys. Res., 97, 875-886, 1992.

Cho, J. Y. N., Alcala, C. M., Kelley, M. C., and Swartz, W. E.: Further effect of charged aerosols on summer mesospheric radar scatter, J. Atmos. Terr. Phys., 58, 661-672, 1996.
Czechowsky, P. and Rüster, R.: Power spectra of mesospheric velocities in polar regions, Handbook of MAP, 18, 207-211, 1985.

Czechowsky, P., Singer, W., Schmidt, G., and Keuer, D.: Technical design of a VHF radar for MST investigations at Andenes, Proceedings of the sixth workshop on technical and scientific aspects of MST radar, Solar-Terrestrial Energy Program, 310-314, 1993.

Dolph, C. L.: A Current Distribution for Broadside Arrays Which Optimizes the Relationship between Beam Width and Side-Lobe Level, Proceedings of the IRE, 34, 335-348, 1946.

Ecklund, W. L. and Balsley, B. B.: Long-term observations of the Arctic mesosphere with the MST radar at Poker Flat, Alaska, J. Geophys. Res., 86, 7775-7780, 1981.

Green, J. L., Clark, W. L., Warnock, J. M., and Ruth, K. J.: Absolute calibration of MST/ST radars, Preprints 21st Conf. on Radar Meteorology, Edmonton, Alberta, Canada, Published by American Meteorol. Society, 114-147, 1983.

Havnes, O., Trøim, J., Blix, T., Mortensen, W., Nsheim, L. I., Thrane, E., and Tønnesen, T.: First detection of charged dust particles in the Earth's atmosphere, J. Geophys. Res., 101, 1082910847, 1996.

Hill, R. J. R.: Nonneutral and quasi-neutral diffusion of weakly ionized multiconstituent plasma, J. Geophys. Res., 83, 989-998, 1978.

Hocking, W. K.: Measurement of turbulent energy dissipation rates in the middle atmosphere by radar techniques: A review, Radio Sci., 20, 1403-1422, 1985.

Hocking, W. K.: Observation and measurement of turbulence in the middle atmosphere with a VHF radar, J. Atmos. Terr. Phys., 48, 655-670, 1986.

Hocking, W. K.: Radar studies of small scale structure in the upper middle atmosphere and lower ionosphere, Adv. Space. Res., 7, 327-338, 1987.

Hocking, W. K.: System design, signal-processing procedures, and preliminary results for the Canadian (London, Ontario)VHF atmospheric radar, Radio Sci., 32, 687-706, 1997.

Hocking, W. K. and Röttger, J.: Studies of polar mesosphere summer echoes over EISCAT using calibrated signal strengths and statistical parameters, Radio Sci., 32, 1425-1444, 1997.

Hocking, W. K. and Vincent, R. A.: A comparison between HF partial reflection profiles from the D-region and simultaneous Langmuir probe electron density measurements, Rev. Sci. Ins., 87, 7615-7624, 1982.

Hocking, W. K., Schmidt, G., and Czechowsky, P.: Absolute calibration of the SOUSY VHF stationary radar, MPAE Report MPAE-W-00-83-14, Max-Planck-Institut für Aeronomie, Katlenburg-Lindau,Germany, 1983.

Hocking, W. K., Kelley, M., Rogers, R., Maurice, J.-P. S., and Moorcroft, D.: Resolute Bay VHF radar: A multi-purpose tool for studies of tropospheric motions, middle atmosphere dynamics, meteor physics and ionospheric physics, Radio Sci., 36, 1839-1857, 2001.

Hoppe, U. P., Hall, C., and Röttger, J.: First observation of summer polar mesosphere backscatter with a $224 \mathrm{MHz}$ radar, Geophys. Res. Lett., 15, 28-31, 1988.

Huaman, M. M., Kelley, M. C., Hocking, W. K., and Woodman, R. F.: Polar mesosphere summer echo studies at $51.5 \mathrm{MHz}$ at Resolute Bay, Canada: Comparison with Poker Flat results, Radio Sci., 36, 1823-1837, 2001. 
Inhester, B., Ulwick, J. C., Cho, J. Y. N., Kelley, M. C., and Schmidt, G.: Consistency of rocket and radar electron density observations: Implication about the anisotropy of mesospheric turbulence, J. Atmos. Terr. Phys., 52, 855-873, 1990.

Kelley, M. C., Farley, D. T., and Röttger, J.: The effect of cluster ions on anomalous VHF backscatter from the summer polar mesosphere, Geophys. Res. Lett., 14, 1031-1034, 1987.

Kirkwood, S., Wolf, I., Nilsson, H., Dalin, P., Mikhaylova, D., and Belova, E.: Polar mesosphere summer echoes at Wasa, Antarctica (73S): First observations and comparison with $68^{\circ} \mathrm{N}$, Geophys. Res. Lett., 34, 9-10, 2007.

La Hoz, C., Havnes, O., Næsheim, L. I., and Hysell, D. L.: Observations and theories of polar mesospheric summer echoes at a Bragg wavelength of $16 \mathrm{~cm}$, J. Geophys. Res., 111, D04203, doi:10.1029/2005JD006044, 2006.

Landecker, T. L. and Wielebinski, R.: The galactic metre wave radiation: A two-frequency survey between declinations $+25 \mathrm{deg}$ and $-25 \mathrm{deg}$ and the preparation of a map of the whole sky, Aust. J. Phys. Suppl., 16, 1-30, 1970.

Latteck, R., Singer, W., Morris, R. J., Hocking, W. K., Murphy, D. J., Holdsworth, D. A., and Swarnalingam, N.: Similarities and differences in polar mesosphere summer echoes observed in the Arctic and Antarctica, Ann. Geophys., 26, 2795-2806, 2008, http://www.ann-geophys.net/26/2795/2008/.

Maronna, R. A., Martin, D. R., and Yohai, V. J.: Robust Statistics: Theory and Methods, Wiley Series in Probability and Statistics, John Wiley and sons Ltd, 2006.

Morris, R. J., Terkildsen, M. B., Holdsworth, D. A., and Hyde, M. R.: Is there a casual relationship between cosmic noise absorption and PMSE?, Geophys. Res. Lett., 32, L24809, doi:10.1029/2005GL024568, 2005.

Rapp, M. and Lübken, F. J.: On the nature of PMSE: Electron diffusion in the vicinity of charged particles revisted, J. Geophys. Res., 108, 8437-8449, 2003.

Rapp, M. and Lübken, F. J.: Polar mesosphere summer echoes (PMSE): Review of observations and current understanding, Atmos. Chem. Phys, 4, 2601-2633, 2004.

Roger, H. V., Costain, C. H., Landecker, T. L., and Swerdlyk, C. M.: The radio emission from the Galaxy at $22 \mathrm{MHz}$, Astron. Astrophys. Suppl. Ser., 137, 7-11, 1999.

Röttger, J.: Reflection and scattering of VHF radar signals from atmospheric reflectivity structures, Radio Sci., 15, 259-276, 1980.

Röttger, J.: Investigation of lower and middle atmopshere dynamics with spaced antenna drifts radars, J. Atmos. Terr. Phys., 43, $277-$ 292, 1981.
Röttger, J.: Observations of the polar D-region and the mesosphere with the EISCAT Svalbard Radar and SOUSY Svalbard Radar, Mem. Nat. Inst. Pol. Res, 54, 9-20, 2001.

Sarango, M. and Woodman, R.: Further observations of PMSE in Antartica, CEDAR Workshop, Colorado, USA, 2003.

Schmidt, G., Ruster, R., and Czechowsky, P.: Complementary Code and Digital Filtering for Detection of Weak VHF Radar Signals from the Mesosphere, IEEE Trans. Geosci. Electron., GE-17, 154-161, 1979.

Sironi, G.: The spectrum of the galactic non-thermal background radiation - I, Mon. Not. R. Astr. Soc, 166, 345-353, 1974.

Swarnalingam, N.: Studies of Polar Mesosphere Summer echoes at multiple sites using calibrated radars, Ph.D. thesis, University of Western Ontario, Canada, 2007.

Swarnalingam, N. and Hocking, W. K.: Calibration and calculation of absolute backscatter cross-section using sky noise and calibrated noise source for Resolute Bay radar, The Eleventh Workshop on Technical and Scientific Aspects of MST Radar, December 2006, Tirupati, India, 2006.

Swarnalingam, N. and Hocking, W. K.: Calibration and calculation of absolute backscatter cross-section using sky noise and calibrated noise source for Resolute Bay radar, Proceedings of the Eleventh Workshop on Technical and Scientific Aspects of MST Radar, December 2006, edited by: Anandan, V. K., 328-333, 2007.

Swarnalingam, N., Hocking, W. K., and Argall, P. S.: Observations and comparisons of polar mesosphere summer echoes in the northern magnetic polar cap region with two calibrated MST radars, COSPAR-2008, Montreal, Canada, 2008.

Thomas, G., Russell III, J. M. R., and Bailey, S.: Polar Mesospheric Cloud properties derived from the NASA Aeronomy of Ice in the Mesosphere Mission (2007-2008), COSPAR-2008, Montreal, Canada, 2008.

Turtle, A. J. and Baldwin, J. E.: A survey of galactic radiation at 178 Mc/s, Mon. Not. R. Astr. Soc., 124, 459-476, 1962.

Webster, A. S.: The spectrum of the galactic non-thermal background radiation - II, Mon. Not. R. Astr. Soc., 166, 355-371, 1974.

Woodman, R. F. and Guillen, A.: Radar Observations of Winds and Turbulence in the Stratosphere and Mesosphere, J. Atmos. Sci., 31, 493-505, 1974. 